\title{
UNA FOTOGRAFÍA DE LA POBREZA DESDE LA INVESTIGACIÓN SOCIAL
}

\section{A PHOTOGRAPHY OF POVERTY FROM SOCIAL RESEARCH}

\author{
Sandra Araya Umaña* \\ Andrea Vásquez Sáenz ${ }^{* *}$
}

RESUMEN

\begin{abstract}
Este artículo sintetiza las diversas aprehensiones del concepto de pobreza, así como, los enfoques para su estudio, lo cual se realizó por medio de un estado del arte que mapeó la investigación en Costa Rica relacionada con la categoría pobreza y su vinculación con la asistencia $y$ la seguridad social durante el período comprendido entre 2000-2011. Como principal hallazgo se encontró que la pobreza es un objeto recurrente de investigación, desde el enfoque de bienestar económico con fuerte influencia de las conceptualizaciones de los organismos internacionales.
\end{abstract}

PALABRAS CLAVE: COSTA RICA * POBREZA * INVESTIGACIÓN SOCIAL * SEGURIDAD SOCIAL * TRABAJO SOCIAL

\section{ABSTRACT}

This article synthesizes the various positionsof the concept of poverty as well as approaches to its study, which was conducted by a literature review mapping research in Costa Rica related with the poverty category and its links with social security assistance between 2000-2011. The main finding was that poverty is a recurrent object of research, from the perspective of economic welfare with strong influence of the conceptualizations of international agencies.

KEYWORDS: COSTA RICA * POVERTY * SOCIAL RESEARCH * SOCIAL SECURITY * SOCIAL WORK

Escuela de Trabajo Social de la Universidad de Costa Rica.

sarayau@ice.co.cr

** Caja Costarricense del Seguro Social, Costa Rica.

andreavs23@gmail.com 


\section{PRESENTACIÓN}

La pobreza es una de las manifestaciones más crudas de las sociedades estructuradas en clases sociales y si bien, ha existido desde épocas anteriores al capitalismo, no se ha manifestado de la misma forma en el desarrollo histórico de la humanidad. Así, en el feudalismo, la pobreza estaba asociada a la escasez, en particular, la alimentaria; mientras que en el capitalismo se vincula a la apropiación privada de la producción social de la riqueza ${ }^{1}$.

Abordada como causa, como efecto o como expresión de una estructura social, los alcances y limitaciones de su conceptualización ha concitado las más diversas posiciones que transitan entre la dificultad de su precisión hasta su posible solución. En virtud de lo anterior y dada la centralidad de la pobreza como categoría de análisis del proyecto de investigación que se asume en la Escuela de Trabajo Social ${ }^{2}$, se realizó un estado del arte cuya elaboración inició con un mapeo de la investigación social relacionada con la categoría pobreza y su vinculación con la asistencia y la seguridad social en el período comprendido entre 2000 2011. Sin embargo, la mención reiterativa de algunos autores en las distintas investigaciones, obligó incluir otras fuentes con independencia de este período y así visibilizar lo que se ha denominado fuentes originales.

Además de las bibliotecas y centros de documentación de la Universidad de Costa Rica (Instituto de Investigaciones Económicas (IIEUCR), Centro Centroamericano de Población (ссP), Escuela de Estadística y el Instituto de Investigaciones Sociales (IIS-UCR)), la búsqueda incluyó instituciones estatales y organizaciones internacionales ${ }^{3}$. Dicha búsqueda arrojó un

$1 \quad$ Para ampliar véase Reppeti, 2013.

2 Proyecto: Trabajo, pobreza, asistencia social y seguridad social: accesibilidad a derechos económicos y sociales en Costa Rica. Escuela de Trabajo Social. Universidad de Costa Rica.

3 Contraloría General de la República (CGR), Instituto Mixto de Ayuda Social (IMAS), Fondo Nacional de Becas (FONABE), Ministerio de Trabajo y Seguridad Social (MTSSs), Ministerio de Educación Pública (MEP), Patronato Nacional de la Infancia (PANI), Instituto Nacional de las Mujeres (INAMU), total de 161 documentos con algún descriptor vinculado a la temática y su posterior análisis precisó la selección de 54. Estos documentos fueron procesados mediante la codificación abierta $^{4}$, lo que permitió el surgimiento de categorías, que aunque son el resultado de nuestro trabajo intelectivo, no fueron una decisión apriorística sino que emanaron de las mismas investigaciones según sus consensos, disensos y tendencias observadas.

El presente artículo muestra los resultados vinculados a la conceptualización de la pobreza desde las instituciones públicas, así como desde las investigaciones efectuadas en Costa Rica durante el período señalado.

\section{LAS IMÁGENES INSTITUCIONALES}

La pobreza es presentada como un eje de actuación central en diversas instituciones públicas de Costa Rica, pero ello no se ha traducido en su delimitación como un objeto de investigación sistemático y sostenido.

El Instituto Mixto de Ayuda Social (ImAs), el Fondo Nacional de Becas (Fonabe), el Patronato Nacional de la Infancia (PanI), el Instituto Nacional de las Mujeres (Inamu), el Consejo Nacional de Rehabilitación y Educación Especial (cNREE), así como, la Comisión Nacional de Asuntos Indígenas (CoNaI) no registran elaboraciones propias relacionadas con la categoría de pobreza, lo cual no exime su definición en sus regla-

Consejo de la Persona Adulta Mayor (CONAPAM), Comisión Nacional de Asuntos Indígenas (CONAI), Facultad Latinoamericana de Ciencias Sociales (FLACSO), Instituto Nacional de Estadística y Censos (INEC), el Programa Estado de la Nación.

4 La codificación abierta comporta dos momentos. El primero se refiere al tratamiento de los datos brutos, los cuales se comparan constantemente. Posteriormente se les asigna un código común a los fragmentos que comparten una misma idea, advirtiendo que en este momento cualquier interpretación es provisional. El segundo es el desarrollo de categorías iniciales, es decir, la búsqueda sistemática de las propiedades de la categoría. Es fundamental que ambos momentos se acompañen del registro de notas teóricas, analíticas e interpretativas. Este segundo momento es el puente con la siguiente operación que implica el descarte, fusión o generación de nuevas categorías (Araya, 2001). 
mentos, programas o planes. De igual forma se encontraron documentos que indirectamente analizan los programas y proyectos desarrollados por estas instituciones para la atención de la población en condición de pobreza.

En contraste, la Contraloría General de la República (CGR) presenta producción teórica sobre la pobreza que se expresa en siete informes (2006a, 2006b, 2006c, 2007, 2008, 2009a y2009b), los cuales, en su totalidad son elaborados con base en las técnicas y procedimientos de la Fiscalización Evaluativa y de la Auditoría Operativa de la Contraloría General de la República ${ }^{5}$.

De igual manera, la Universidad de Costa Rica (UCR), la Facultad Latinoamericana de Ciencias Sociales(flacso), el Instituto de Investigaciones Económicas de la UCR (IIE-UCR), el Centro Centroamericano de Población(ccp), Programa Estado de la Nación y el Instituto de Investigaciones Sociales de la UCR (IIS-UCR) contienen un rico material investigativo con respecto al descriptor pobreza.

\section{EL CONCEPTO DE POBREZA}

Un número considerable de investigaciones precisan definiciones de pobreza vinculadas al enfoque de bienestar económico. Esto se explica porque es uno de los enfoques de más larga data y por la definición de pobreza, a partir de dos indicadores de carácter económico muy tangibles: los ingresos y el consumo. Desde este enfoque, la carencia de ingresos suficientes para adquirir un nivel básico de consumo o de bienestar humano es el determinante de la pobreza.

Las investigaciones de Ávalos, Escalante $y$ Soto (2004), Mora (2004), Monge y Rivera (2005), cGR (2006b), Barahona (2007), López (2009), Mora y Ramírez (2010), coinciden en

$5 \quad$ Estas técnicas y procedimientos refieren al "análisis y síntesis del contenido de presupuestos institucionales, leyes, decretos ejecutivos, reglamentos, pronunciamientos de la Sala Constitucional y de la Procuraduría General de la República, expedientes de la Asamblea Legislativa sobre proyectos de ley, estudios realizados por la Contraloría General de la República y literatura teórica y aplicada sobre gestión pública, reforma del Estado y política social" (CGR, 2006b: 6). esta definición y en algunas se resalta el comportamiento diferenciado de la pobreza según sea el momento histórico.

No obstante, la investigación que aborda la pobreza de manera exhaustiva desde el carácter histórico es la de Hernández, Masis y Quesada (2010) quienes la evidencian como una secuela de la "cuestión social":

[la explicación de la pobreza] desde el materialismo-dialéctico se centra en la Ley General de Acumulación Capitalista, como máxima expresión de la relación antagónica capital-trabajo, generadora $y$ potenciadora de desigualdad social; así como instrumento necesario para la concentración y acumulación de capital (Hernández, Masís y Quesada, 2010: 63).

De la misma manera, Coto y Salgado (2008) hacen un análisis novedoso desde los discursos de la teología latinoamericana y la teología de la prosperidad. Los autores visualizan que desde la primera, la pobreza es entendida como producto de relaciones sociales injustas o del pecado estructural y desde la segunda, como un problema individual en donde las maldiciones, el pecado y los demonios intervienen para su reproducción.

Por otra parte, existen investigaciones que comprenden la pobreza como un factor de riesgo que genera migración (Aragón, 2005), como causa de desempleo, de drogadicción y delincuencia (Aguilar y Brenes, 2008a y 2008b) y como una condición que agudiza la desigualdad de género (Gordon, 2010).

En contraste con lo anterior, otras investigaciones señalan la pobreza como causa $y$ efecto, por tanto, la convierte en un fenómeno complejo, multifactorial $y$ de difícil definición. Astúa y Solano (2000); Carmona, Ramos y Sánchez (2005); Cruz, Marín y Santamaría (2005); González, Jiménez y Madrigal (2006); Barquero y Bonilla (2007); Castro y Chévez (2009); coinciden en esta conceptualización.

Si bien muchas investigaciones no necesariamente señalan los referentes que las nutren, es posible identificar en estas el enfoque de capacidades desarrollado por Amartya Sen. 
Sen (2000) señala elementos como oportunidades, capacidades, elecciones, bienestar y libertad, con el fin de ampliar el conocimiento sobre pobreza, pues según su tesis, desde el análisis clásico (ingresos), la pobreza es reducida a lo económico, alejando particularidades concretas como la desigualdad por sexo o por incapacidad.

Cruz, Marín y Santamaría (2005), Instituto de Estudios Sociales en Población-IDEsPo (2004) y López (2009) colocan en sus referentes conceptuales, el enfoque de Sen combinado con el enfoque de derechos pues indican que la pobreza atenta contra las posibilidades de satisfacción de las necesidades humanas de sujetos corpóreos, sus familias y comunidades, por tanto, es una violación flagrante de derechos humanos de la población que la sufre.

Doz (2008) indica que existen tres maneras de aprehender la pobreza como una violación a los derechos humanos y cada una tiene implicaciones éticas y jurídicas que determinan su abordaje a nivel local e internacional, a saber: 1) pobreza como una violación de derechos humanos en sí misma, 2) pobreza como una violación a un derecho humano específico, a saber el derecho a un nivel adecuado de vida o al desarrollo, 3) pobreza como una causa o consecuencia de violaciones a los derechos humanos.

Esta autora cuestiona el enfoque de derechos, pues indica su reducción a un eslogan vacío e infructuoso. Lessa (2007) coincide en la crítica al enfoque de derechos humanos y señala que la supuesta búsqueda de un mundo igualitario para todas las personas, ignora el sistema económico imperante y el predominio idealizado de los derechos sociales sobre los económicos.

Por su parte, Hayes (2004) afirma que debido a su carácter relativo y multidisciplinario, la pobreza es una situación difícil de comprender, contextualizar e interpretar como objeto de estudio. Ello contrasta con otros autores y autoras que proponen formas clasificatorias de la pobreza y así de esta manera señalan: la crítica (Jones, 2002), la crónica, la transitoria y la vulnerabilidad (Marques, 2004), la primaria (Carmona, Ramos y Sánchez, 2005), pobreza de renta, pobreza como privación de capacidades, pobreza como ingreso insuficiente (Cruz, Marín y Santamaría, 2005) y pobreza rural (Calvo, 2011).

La pobreza clasificada como crítica y crónica es comprendida desde los factores estructurales (relaciones sociales de producción) y la transitoria como aquella con posibilidad de revertirse con el tiempo. Por su parte, la vulnerabilidad es percibida desde la capacidad de resistencia de una persona o familia a un determinado shock, según sea su impacto. Las otras distinciones responden más al enfoque económico, es decir, a la relación ingresos y consumo, agregando otros factores como el origen étnico y el género (pobreza rural).

En general, se puede afirmar que estas distinciones entremezclan elementos de los enfoques mencionados $y$ su aporte es poco significativo con respecto a la conceptualización de la pobreza.

El análisis crítico de la pobreza se presenta en un número reducido de investigaciones, las cuales concuerdan en la existencia de una dimensión política ideológica que media la comprensión y "planes de combate" a la pobreza. Esta dimensión permite la "institucionalización" de la pobreza como un "problema social que afecta a ciertos grupos" y le da al Estado la potestad de configurar nuevas formas de organización $y$ regulación de la vida social; al mismo tiempo que permite desviar el foco de atención de las causas originarias de la pobreza, las cuales tienen su génesis en el sistema de producción (Hernández, Masís y Quesada, 2010; Cubillo, 2011; López, 2007; Mondol, 2007 y Prado, 2010).

Otro enfoque presente en las investigaciones es el enfoque culturalista, el cual emergió durante los años 60 en el contexto de la industrialización en América Latina y se resume en la existencia de una "cultura de la pobreza”, concepto definido por Oscar Lewis:

Es una cultura en el sentido antropológico tradicional en el que el ser humano es provisto de una forma con un conjunto prefabricado de soluciones para los problemas humanos, $y$ por lo tanto tiene una función adaptativa significativa. Este estilo de vida trasciende las fronteras nacionales $y$ las diferencias regionales $y$ 
rurales-urbanas dentro de las naciones. Donde quiera que ocurra, las personas que la viven exhiben notable similitud en la estructura de sus familias, en las relaciones interpersonales, en los hábitos de consumo, en sus sistemas de valores y en el uso del tiempo (traducción libre de las autoras) (1966: 19).

Para Astúa y Solano (2000), este enfoque es criticable porque no establece claramente si los factores asociados con la cultura son causas de la pobreza o el resultado de circunstancias enfrentadas por las personas pobres.

Otro enfoque presente en las investigaciones es el de exclusión social, el cual surgió en América Latina en el contexto de la crisis del Estado Benefactor (finales de la década del 70) $y$ en el contexto de los Programas de Ajuste Estructural. Al igual que el culturalista, recoloca la responsabilidad de la pobreza en los sujetos individuales y los conceptos de "justicia social", "participación social" y "redes sociales" son abordados dentro la óptica de la focalización, la condicionalidad $y$ la delegación de responsabilidades estatales en organizaciones de la sociedad civil (Tercer Sector). Los autores Gacitúa, Sojo y Davis explican que la exclusión social es:

La imposibilidad de un sujeto o grupo social para participar efectivamente a nivel económico, social, cultural, político e institucional... [que] incluye tres dimensiones: (i) económica, en términos de privación material y acceso a mercados y servicios que garanticen las necesidades básicas; (ii) política e institucional en cuanto a carencia de derechos civiles y políticos que garanticen la participación ciudadana y; (iii) sociocultural, referida al desconocimiento de las identidades y particularidades de género, generacionales, étnicas, religiosas o las preferencias o tendencias de ciertos individuos y grupos sociales (2000: 14).

Como se puede observar, subyace la noción de vulnerabilidad, considerada como un elemento que caracteriza a la pobreza en tanto las personas pobres están más expuestas y con menos capacidad de respuesta a los impactos externos que están fuera de su control tales como: enfermedades, violencia y desastres naturales, entre otros (Trejos, 2011).

Astúa y Solano (2000), Corrales (2010), Prado (2010), Vargas (2009) y Hayes (2004), refieren a este enfoque y coinciden en que la pobreza es un componente central de la exclusión social, la cual es retomada como un proceso en la que se evidencian tres dimensiones: la política, la económica y la socio-cultural. Según sus postulados, la pobreza se constituye en una consecuencia o resultado del funcionamiento de procesos paralelos de exclusión social y por tanto, en una más de sus manifestaciones.

Cabe resaltar que este enfoque fue utilizado inicialmente en Europa Occidental (Francia, Italia y los países nórdicos); no obstante, en América Latina se ha utilizado con algunas variaciones y de ahí devienen sus principales críticas. Verdera (2007) señala que responde a una realidad social y a una respuesta propia de otras latitudes, lo cual obvia la condición de pobreza generalizada, la escasa cobertura de los sistemas de asistencia y seguridad, así como, la conculcación sistemática de derechos económi$\cos y$ sociales que caracterizan a los distintos países de América Latina.

En consonancia con el enfoque de exclusión, Ávalos, Escalante y Soto (2004), Brenes y Chacón (2009) y Chinchilla (2000), señalan que en la comprensión de la pobreza se debe tomar en cuenta las dimensiones de la marginalidad, la discriminación, la desigualdad y la inequidad.

En síntesis, es evidente el esfuerzo que en las distintas investigaciones se hace por definir la pobreza. En algunas de estas, hay claridad acerca del enfoque en que se finca la conceptualización utilizada y en otras, es una adición sin reflexión que poco contribuye con el debate teórico acerca del concepto.

No obstante, es menester rescatar que el tema de la pobreza es foco de interés de investigadores e investigadoras de diferentes disciplinas, lo cual está en consonancia con su magnitud y relevancia. Si bien, hay distintas explicaciones y un sinnúmero de descripciones, en particular de naturaleza estadística, la referencia a la base material como eje constitutivo 
de la pobreza, con algunas claras excepciones, es escasamente abordada.

Lo anterior desde el punto de vista de las autoras, es producto de la lógica positivista causa-efecto, en la que captar lo estático, lo aparente y transcribirlo con descripción empírica, es reconocido como sinónimo de conocimiento científico. Se ignora o se resta importancia al conjunto de mediaciones que intervienen en la aparición y consolidación de la pobreza y a la recuperación de la esencia de los hechos sociales con respecto a su origen en un modo de producción. Por ende, es conveniente que desde las ciencias sociales y en particular, desde el Trabajo Social, se trascienda de lo aparencial para recuperar las mediaciones que atraviesan la pobreza, principalmente, las que tiene que ver con una sociedad constituida según clase social, género y etnia.

\section{LAS FUENTES REFERENCIALES}

En las distintas investigaciones es relevante la constante referencia a las definiciones de organismos internacionales, tales como: la Comisión Económica para América Latina (cEpal), el Banco Mundial (вм) y el Programa de las Naciones Unidas para el Desarrollo (PNuD). En algunas se accede de manera directa a estas fuentes, pero en otras, se llega a estas por medio de otras investigaciones.

Se constata que en algunas se registran las fuentes de manera deficiente o incorrecta $y$ que las referencias se convierten en una suerte de "reciclaje" que en ocasiones, causan confusiones conceptuales.

Por lo anterior, se transcriben las definiciones que de manera explícita ( $y$ otras veces no tanto), son mayormente mencionadas en las investigaciones. 


\section{TABLA 1 \\ DEFINICIONES DE POBREZA SEGÚN AUTOR O AUTORA \\ (FUENTE PRIMARIA)}

\section{REFERENCIA BIBLIOGRÁFICA}

Alayón (2000: 1126)
DEFINICIÓN DE POBREZA

\begin{tabular}{l} 
Alayón (2000: 1126) \\
\\
\hline Altimir (1979: 1) \\
Definición asumida \\
por la CEPAL.
\end{tabular}

Altimir (1979: 1) por la CEPAL.

Los fenómenos de la pobreza no responden a causas naturales (como por ejemplo, determinadas catástrofes climatológicas) ni a designios divinos, ni a responsabilidades individuales de los propios damnificados. Tienen un origen social, ligado a las características que predominan en el funcionamiento de la sociedad.

Es un síndrome situacional en el que se asocian el infraconsumo, la desnutrición, las precarias condiciones de vivienda, los bajos niveles educacionales, las malas condiciones sanitarias, una inserción inestable en el aparato productivo o dentro de los estratos primitivos del mismo, actitudes de desaliento y anomia, poca participación en los mecanismos de integración social y quizás, la adscripción a una escala particular de valores, diferenciada en alguna medida de la del resto de la sociedad.

Banco Interamericano Es la falta de acceso o dominio de los requisitos básicos para mantener un nivel de vida de Desarrollo (1997:5) aceptable. Esto significa que una persona es pobre si no tiene suficiente comida o carece de acceso a una combinación de servicios básicos de educación, atención en salud, agua potable, sistemas de saneamiento adecuados y un lugar de residencia seguro. Generalmente, los economistas usan el ingreso como medida representativa de la pobreza porque brindan los medios para asegurar la atención debida a las demás necesidades básicas. Por tal razón, la mayoría de las estrategias para combatir la pobreza, incluida esta, dedican suma atención a la generación de ingreso como la solución del problema.

Banco Mundial (2000) La pobreza es el resultado de los procesos sociales, políticos y económicos que interactúan entre Definición asumida sí y que con frecuencia se refuerzan mutuamente de forma que exacerban la penuria en que por la CGR (2009a) viven las personas pobres (2002: 1).

La pobreza se manifiesta en una privación de bienestar. Pero ¿cuál es exactamente la privación? Las voces de las personas pobres dan testimonio elocuente de su significado... Ser pobre es tener hambre, no tener vivienda ni vestido, es enfermarse y no ser atendido, ser analfabetos $y$ no escolarizado. Pero para la gente pobre, que vive en la pobreza, es más que esto. Personas especialmente pobres son vulnerables a los efectos adversos fuera de su control. A menudo maltratadas por las instituciones del Estado y la sociedad $y$ excluidas de la voz $y$ el poder en esas instituciones (2000: 14) (traducción propia).

Céspedes y Jiménez La pobreza, por consiguiente, no solo muestra una gran variedad de caras como reflejo de (1995: 7) Situaciones y condiciones específicas distintas, en el tiempo y espacio, de las poblaciones consideradas, sino, además, es un fenómeno muy complejo en cuanto a sus relaciones de causalidad. Todo lo cual dificulta su conceptualización y hace mucho más difícil su análisis y el diseño de las políticas para enfrentarla.

IMAS (2011: 7) Fenómeno o situación compleja de índole coyuntural o estructural, multifacético y heterogéneo, que afecta a las personas y que se caracteriza por sus precarias condiciones de vivienda y sanitarias, bajos niveles educacionales, inserción inestable en el sistema productivo, condiciones de riesgo social, con poca o ninguna incorporación en mecanismos de participación social, recursos insuficientes para satisfacer necesidades básicas (nutricionales, salud, educación y vivienda) y en algunos casos ausencia o insuficiencia de destrezas, aptitudes, herramientas $y$ oportunidades para generar $y$ acumular ingresos. 


\section{REFERENCIA BIBLIOGRÁFICA}

DEFINICIÓN DE POBREZA

\begin{abstract}
Mejívar y Trejos (1992) Es un fenómeno multifacético, fácil de percibir pero difícil de definir con precisión y más aún de medir adecuadamente. El carácter normativo que envuelve el concepto... representa una dificultad básica, tanto para la definición de políticas adecuadas de alivio y erradicación... Como apunta Altimir (1979:3) "En el estado actual de nuestra comprensión del síndrome de la pobreza no existe un marco teórico en el que este explique satisfactoriamente en su totalidad, atendiendo a la presencia simultánea de los síntomas que la componen sólo existen explicaciones aisladas de cada uno de ellos como casos extremos de desigualdad en un subsistema particular de distribución de bienes". Esta imprecisión teórica del concepto impide considerar a los pobres como "... un grupo social en sentido estricto, cuyos orígenes comportamiento y relaciones con el resto de la sociedad sean comunes" (1992: 13-14).

Es la presencia de niveles de vida o bienestar socialmente inaceptables. Esta inaceptabilidad puede aludir a una dimensión absoluta del fenómeno, es decir, corresponder a situaciones en que está en juego la propia existencia del individuo o puede tener un carácter más relativo, esto es, referirse a condiciones de marginación con relación a los niveles medios de vida que ostenta la sociedad específica en un momento de tiempo dado. Estos niveles de privación serán producto a su vez o son acompañados de carencias en la formación de habilidades y destrezas de los individuos, así como de activos físicos, necesarios ambos para la generación de ingreso adecuado y para tener posibilidades de acumulación posterior. Esto implica que la privación es acompañada por la incapacidad de las personas que la sufren de cambiar la situación por sí mismas, incapacidad que se refuerza por la falta de acceso al poder político para encontrar apoyo a la resolución de sus limitaciones (1992: 15).
\end{abstract}

Narayan (2000: 18) La pobreza es multidimensional y tiene importantes dimensiones no económicas. Es siempre específica de un lugar y un grupo social, es esencial tener en cuenta estas características específicas en la elaboración de políticas y programas destinados a combatirla. A pesar de las diferencias en el modo en que viven la pobreza los diversos grupos en diversos lugares, hay sorprendentes elementos comunes a la experiencia de la pobreza en países muy distintos, de Rusia a Brasil, de Nigeria a Indonesia. La vida de los pobres se caracteriza por la impotencia y la falta de representación en las decisiones, lo que limita sus posibilidades de elección y define la calidad de su relación con los empleadores, los mercados, el Estado e incluso con las organizaciones no gubernamentales (ONG). El acceso de los pobres a las oportunidades, se ve limitado por la intermediación de instituciones formales e informales.

OMS (1995: 1) La pobreza es la principal razón de que los bebés no sean vacunados, el agua potable y el saneamiento no se proporcionen, de que los medicamentos y otros tratamientos curativos no estén disponibles y del por qué las madres mueren en el parto. La pobreza es la principal causa de la reducción de la esperanza de vida, de la discapacidad y de la inanición. La pobreza es un factor que de manera significativa contribuye con las enfermedades mentales, el estrés, el suicidio, la desintegración familiar y el abuso de sustancias. Impone su influencia destructiva en todas las etapas de la vida humana, desde el momento de la concepción hasta la tumba (traducción propia).

PNUD (2002:2) Es la ausencia y la denegación del desarrollo humano. Por consiguiente, su causalidad y los rasgos principales de su caracterización se encuentran íntimamente relacionados con la carencia de oportunidades y opciones esenciales en la vida de una persona y con fallas en las capacidades básicas. Allí se ubican la carencia de recursos, la insatisfacción de necesidades básicas y la escasa participación de los pobres vinculada con la ausencia de voz, poder y representación.

Es privación con respecto a un conjunto de dimensiones relevantes para el desarrollo humano, entendidas como fallas en las capacidades básicas, las cuales se relacionan con las condiciones de vida y el acceso a servicios y programas sociales. Si bien, algunas de las variables utilizadas - como analfabetismo y acceso a los servicios de salud y agua potable - forman parte del índice de pobreza humana, se trata de analizar un conjunto más amplio de variables, consideradas como posiblemente asociadas a la condición de pobreza, tanto por ingreso como por necesidades básicas insatisfechas. 
REFERENCIA BIBLIOGRÁFICA
DEFINICIÓN DE POBREZA
Sauma (2011)

\begin{abstract}
Pobreza y desarrollo son conceptos íntimamente relacionados. Si bien ambos son complejos, y no existen definiciones que se puedan denominar "de consenso", en términos generales el desarrollo se refiere al avance de los países en el logro de mayores niveles de bienestar para la población, mientras que la pobreza se refiere precisamente a la prevalencia entre la población de elevados niveles de insatisfacción de algunas necesidades consideradas como básicas. Para efectos de la presente investigación se concibe el bienestar en los términos propuestos por Sen (1987), esto es, la capacidad de la población de "funcionar" en sociedad, que implica que la población disponga de capacidades básicas y tenga adecuados niveles de ingreso, educación, salud, seguridad y libertad. La pobreza se refiere a la carencia o insuficiencia en los mismos (2011: 23).
\end{abstract}

Sen (2000: 114-115) Debe concebirse como la privación de capacidades básicas y no meramente como la falta de ingresos, que es criterio habitual con el que se identifica la pobreza. La perspectiva de la pobreza basada en las capacidades no entraña el rechazo de la razonable idea de que la falta de renta es una de las principales causas de la pobreza, ya que la falta de renta puede ser una importante razón por la que una persona está privada de capacidades.

De hecho, la falta de renta predispone claramente a llevar una vida pobre. Si se acepta esta premisa, ¿a qué viene todo este jaleo de observar la pobreza desde la perspectiva de las capacidades (en lugar de observarla desde la perspectiva habitual de la renta)?

Se señaló como los puntos a favor del enfoque de pobreza, basado en las capacidades, los siguientes:

1) La pobreza puede identificarse de forma razonable con la privación de capacidades; el enfoque de la atención en las privaciones que son intrínsecamente importantes (a diferencia de la renta baja, que solo es instrumentalmente importante).

2) Hay otros factores que influyen en la privación de capacidades — por lo tanto, en la pobreza real- además de la falta de renta (la renta no es el único instrumento que genera capacidades).

3) La relación instrumental entre la falta de renta y la falta de capacidades varía de unas comunidades a otras, incluso de unas familias a otras y de unos individuos a otros (la influencia de la renta en las capacidades es contingente y condicional).

Sojo (1997) Es particularmente difícil de caracterizar por tratarse de una condición altamente heterogénea que incluye tanto a individuos ligados al sector productivo dominante como a quienes sobreviven al margen de la economía formal. Indica privaciones extremas y grados menos dramáticos de satisfacción de necesidades. Establece cohortes sociales, grupos diferenciados a partir de la presencia de la condición o de su ausencia: la pobreza es estigma (1997: 13).

El fenómeno de la pobreza está asociado a una paradoja: todo el mundo la reconoce al verla pero existe muy poco consenso sobre su definición y consecuentemente, su ponderación. No existe un paradigma dominante en la investigación. La disputa en las definiciones y explicaciones científicas produce a su vez una diversidad de métodos destinados a la medición y el reconocimiento empírico sobre la pobreza (1997: 17).

Trejos (1995: 1) La pobreza es un fenómeno multifacético y heterogéneo, difícil de definir con propiedad, explicar teóricamente en forma comprensiva y medir satisfactoriamente. Conceptualmente, la pobreza resume una situación de privación o impotencia. Privación, porque los individuos no disponen de ingresos ni de activos suficientes para satisfacer sus necesidades materiales elementales y ello es producto de la ausencia de educación, destrezas, actitudes, herramientas, oportunidades o activos suficientes para generar ingresos y acumular. Impotencia porque no poseen ni la organización, ni el acceso al poder político para cambiar la situación por sí solos.

Fuente: Elaboración propia con base en fuentes originales. 
Se puede observar la prevalencia del enfoque de capacidades $y$ de bienestar económico en las definiciones anteriores, en particular en las de organismos internacionales. Según criterio propio, esto es producto del anclaje de dichos organismos en el enfoque de bienestar económico (ingresos $y$ consumo), con lo cual se des-economiza, des-historiza y a-politiza el modo de producción capitalista en su papel de potenciador $y$ generador de pobreza.

La definición de Altimir (1979), a pesar de haber sido formulada hace más de 30 años, cabe resaltar que es retomada de manera, es producto de su carácter prescriptivo al aportar elementos de manera sinóptica en cuanto a las características de la pobreza. Incluso, es notorio, que la definición asumida por el IMAs es análoga a esta.

Por último, se señala que Céspedes y Jiménez (1995), Sojo (1997) y Menjívar y Trejos (1992) refieren a las dificultades de precisar el concepto (aspecto de igual manera recurrente en muchas de las investigaciones analizadas) $y$ terminan adhiriéndose a las definiciones normativas. En este sentido, se reconoce que aunque no refieren a su base material explicativa, la caracterización de la pobreza desde las singularidades de los grupos que la viven, tal y cual lo ponen en relieve algunos organismos internacionales (PNUD, омs, FMI), es un elemento que necesariamente debe ser recuperado, pues obliga a colocar la mirada en las situaciones específicas.

No obstante, se debe trascender el análisis de la individualidad y recuperar la mediación de la singularidad para así ubicar a las personas, no por el problema, sino por ser personas. Así de esta manera, se rescataría al individuo como la menor unidad de la totalidad social y por ende, como portador de variaciones infinitas de gran complejidad social (clase social, género, etnia, entre otras) articuladas entre sí por un sistema de mediaciones. Indudablemente, el análisis superaría la lógica racional positivista para colocar el acento en el análisis de la totalidad social.

\section{A MANERA DE COROLARIO}

La pobreza se ha configurado como un objeto recurrente de investigación desde $1967^{6}$, año en el que es posible identificar producciones académicas que procuraban su explicación. Cuarenta años después, continúa como eje significativo de la investigación social en su afán de explicarla, comprenderla, combatirla y algunas otras más osadas, erradicarla.

Hay esfuerzos investigativos significativos que procuran su mayor comprensión por medio de un análisis crítico que evidencia la dimensión política, el poder de los grupos dominantes y la injerencia de los organismos internacionales en la configuración de las comprensiones y "planes de combate" a la pobreza.

Desde esta propia investigación, se adscribe a la comprensión de la pobreza como expresión de la "cuestión social", entendiendo por esta, la contradicción de las sociedades capitalistas en las que hay una distribución desigual de la riqueza producida socialmente. Es la manifestación, en el cotidiano de la vida social, de la contradicción entre el proletariado y la burguesía (Iamamoto y Carvalho, 1983).

La mayor recurrencia de investigaciones precisan definiciones de pobreza vinculadas al enfoque de bienestar económico y otras lo entremezclan con el enfoque de capacidades, de exclusión social y de derechos humanos. En este sentido, el economista hindú Amartya Sen, es un autor bastante referenciado pues, en efecto, su principal contribución consiste en aportar otras aristas distintas al consumo y al ingreso.

En concordancia con lo anterior, la tendencia de las instituciones vinculadas a la asistencia y la seguridad social en Costa Rica, es asumir el enfoque de bienestar económico en el plano operativo, por consiguiente, los otros enfoques (cuando se mencionan) se limitan al plano discursivo y normativo.

Por lo anterior, las distintas conceptualizaciones de las que parten las instituciones reproducen los contenidos de las definiciones de los organismos internacionales.

\footnotetext{
$6 \quad$ Estos estudios no fueron incluidos dada la delimi-
} tación temporal de la presente investigación. 
Se enfatiza los aportes investigativos que dimensionan la pobreza, el género y la etnia, pues en definitiva, junto con la clase social, constituyen los principales ejes de desigualdad.

Estos hallazgos son de especial relevancia para el Trabajo Social y otras disciplinas de las ciencias sociales, cuyo trabajo profesional está vinculado con los sectores despojados de sus derechos económicos y sociales pues, para avanzar en la construcción de sociedades más justas y democráticas, es preciso poseer claridad teórica y metodológica acerca de la pobreza, sus causas y su papel en la reproducción de las condiciones que generan desigualdad.

\section{BIBLIOGRAFÍA}

LIBROS

Alayón, Norberto. Asistencia y asistencialismo ¿Pobres controlados o erradicación de la pobreza? Buenos Aires, Argentina: Grupo Editorial Lumen Hvmanitas, 2000.

Altimir, Oscar. La dimension de la pobreza en América Latina. Santiago, Chile: Publicaciones de las Naciones de Unidas, 1979.

Banco Interamericano de Desarrollo-Bid. Estrategias para reducir la pobreza. Washington, Estados Unidos: Banco Interamiericano de Desarrollo, 1997.

Banco Mundial-вм. World Development Report 2000/2001: atacking poverty: opportunity, empowerment and security. Washington, eeuv: Banco Mundial, 2000.

Céspedes, Victor y Jiménez, Ronulfo. La pobreza en Costa Rica: concepto, medición y evolución. San José, Costa Rica: Editorial Academia de Centroamérica y Centro Internacional para el Desarrollo Económico, 1995.

Gacitúa, Estalisnao; Sojo, Carlos y Davis, Shelton. Exclusión social y reducción de la pobreza en América Latina y el Caribe. San José, Costa Rica: Facultad Latinoamericana de Ciencias SocialesFLACSO, 2000.

Iamamoto, Marilda y Carvalho, Raul. Relaciones sociales y servicio social. São Paulo, Brasil: Cortez Editora, 1983.
Menjívar, Rafael y Trejos, Juan Diego. La pobreza en América Central. San José, Costa Rica: Facultad Latinoamericana de Ciencias Sociales-flacso, 1992.

Organización Mundial de la Salud. The world health report 1995-bridging the gaps. Geneva, Suiza: Organización Mundial de la Salud-oms, 1995.

Programa de las Naciones Unidas. Desarrollo humano y pobreza. Programa de las Naciones Unidas-pNud, 2002.

Sen, Amartya. Desarrollo y libertad. Buenos Aires, Argentina: Editorial Planeta SA, 2000.

Sojo, Carlos. Los de en medio: la nueva pobreza en Costa Rica. San José, Costa Rica: Facultad Latinoamericana de Ciencias Sociales-rLacso, 1997.

Verdera, Francisco. La pobreza en el Perú: un análisis de sus causas y de las políticas para enfrentarla. Lima, Perú: Instituto de Estudios Peruanos-iep, Consejo Latinoamericano de Ciencias SocialesCLACSO, 2007.

Trejos, Juan Diego. La pobreza en Costa Rica: una síntesis cuantitativa. San José, Costa Rica: Instituto de Investigaciones en Ciencias Económicas-IIce, 1995.

Trejos, Juan Diego. Pobreza, desigualdad y oportunidades: una visión de largo plazo. San José, Costa Rica: Instituto de Investigaciones Económicas-IIce, 2011.

\section{FUENTES PERIÓDICAS}

Barahona, Manuel. "La política social y la institucionalidad pública costarricense en el marco del estancamiento en los índices de pobreza 1994-2006". Revista Centroamericana de Ciencias Sociales 2 (4).San José, Costa Rica. Facultad Latinoamericana de Ciencias SocialesFLACSO, diciembre 2007: 31-69.

Barquero, Jorge y Bonilla, Jorge. "Estimaciones de pobreza para áreas pequeñas en Costa Rica: una aplicación de los estimadores de contracción de James-Stein". Revista de Matemática: Teoría y Aplicaciones 2 (14). San José, Costa Rica. Universidad de Costa Rica, 2007: 183-192. 
Cubillo, Marcela. "Reflexiones críticas sobre los estudios de pobreza en Costa Rica". Revista Nacional de Administración 2 (1). San José, Costa Rica. Universidad Estatal a Distancia, 2011: 111-124.

Instituto de Estudios Sociales en Poblaciónidespo. "Percepción de la población costarricense sobre la situación socioeconómica del país pobreza y vulnerabilidad". Perspectiva 21. Universidad Nacional de Costa Rica, 2004.

López, M. "Políticas de interpretación, validación y legitimación de la atención a la pobreza en el régimen de bienestar social costarricense: sobre el discurso del imas(1994-2002)". Revista Centroamericana de Ciencias Sociales 4. San José, Costa Rica. Facultad Latinoamericana de Ciencias Sociales-flacso, julio 2007. En: <http:// unpan1.un.org/intradoc/groups/public/ documents/icap/unpan034532.pdf>.

Lessa, Sergio. "A emancipação politica e a defensa de direitos". Servicio Social e Sociedade 90 (28).São Paulo, Brasil. Cortez Editora, 2007: 35-57.

Lewis, Oscar. "The culture of poverty". Scientific American Magazine 4 (215). New York, eeuu. Scientific American, octubre 1966: 19-25.

Marques, José. "Evaluaciones de las redes de seguridad social de Centroamérica: análisis de los principales hallazgos". Desafios del desarrollo social en Centroamérica. 2004: 191-252.

Mora, Minor. "El lado oscuro de la medición de la pobreza. Reflexiones a partir del caso costarricense". Revista Centroamericana de Ciencias Sociales 2. San José, Costa Rica. Facultad Latinoamericana de Ciencias Sociales-flacso, diciembre 2004: 75-104.

Narayan, Deepa. "La pobreza es impotencia y falta de representación". Finanzas y desarrollo. Washington dc, eEuu. Fondo Monetario Internacional, diciembre 2000: 18-21.

Sauma, Pablo. "Las desigualdades intrarregionales y la reducción de la pobreza en la región Chorotega". Serie de Divulgación Económica. San José, Costa Rica. Instituto de Investigaciones Económicas, 2011: 9-92.

\section{TESIS NO PUBLICADAS}

Aguilar, Maricarmen y Brenes, Gabriela. "Percepción del riesgo en hombres $y$ mujeres, en situación de riesgo ante desastres: tomando como caso la Comunidad de las Vegas de Sixaola”. [Tesis de Licenciatura en psicología]. San José, Costa Rica: Universidad de Costa Rica, 2008a.

Aragón, Margarita. "Las adolescentes migrantes nicaragüenses en Costa Rica: entre la migración, la pobreza y la condición de género". [Tesis de Maestría en estudios de la mujer]. Heredia, Costa Rica: Universidad Nacional de Costa Rica, 2005.

Araya, Sandra."La equidad de género desde la representación social de las formadoras $y$ los formadores del profesorado de segunda enseñanza". [Tesis de Doctorado en Educación]. San José, Costa Rica: Universidad de Costa Rica, 2001.

Astúa, Ivonne y Solano, Priscilla. "Indigencia: referentes generales en torno a este fenómeno social". [Tesis de Licenciatura en Trabajo Social]. San José, Costa Rica: Universidad de Costa Rica, 2000.

Ávalos, Andrés; Escalante, Isabel y Soto,Victoria. "Derecho al desarrollo $y$ marginalidad". [Seminario de Graduación de Licenciatura en Derecho]. San José, Costa Rica: Universidad de Costa Rica, 2004.

Brenes, Maigualida y Chacón, María. "Intervención con personas en situación de indigencia: un análisis crítico en cuatro organizaciones no gubernamentales". [Tesis de Licenciatura en Trabajo Social]. San José, Costa Rica, 2009.

Calvo, Hari. "Evaluación de efectos de las iniciativas económicas innovadoras del Programa de Desarrollo Sostenible de Amigos de la Tierra España en las comunidades transfronterizas de Upala 
(Costa Rica) y el refugio de vida silvestre Los Guatusos (Nicaragua)". [Tesis de Maestría en Evaluación y programas de desarrollo]. San José, Costa Rica: Universidad de Costa Rica, 2011.

Carmona, Keylor; Ramos, Mario y Sánchez, Fernando. "Dimensión espacial de la pobreza, desigualdad y polarización en Costa Rica incorporando el principio de la línea de ingreso, período 2000-2001". [Tesis de Licenciatura en Economía]. San José, Costa Rica: Universidad de Costa Rica, 2005.

Castro, Alejandra y Chévez, Diandra. "Costa Rica: ¿crecimiento pro pobre durante el periodo 1990-2006?". [Seminario de Graduación de Licenciatura en Economía]. San José, Costa Rica: Universidad de Costa Rica, 2009.

Chinchilla, Luisa. "Las cooperativas de mujeres de maquila. Una expresión significativa de la pobreza. El caso de Coopevilla". [Tesis de Maestría en Administración Pública con énfasis en cooperativismo]. San José, Costa Rica: Universidad de Costa Rica, 2000.

Corrales, Mauricio. "Modelo de desarrollo $y$ exclusión social en Costa Rica: una caracterización a partir de las encuestas de hogares de propósitos múltiples". [Tesina]. San José, Costa Rica: Coordinación Educativa y Cultural Centroamericana, 2010.

Coto, Pablo y Salgado, Moises. "Los discursos y las representaciones sociales acerca de la pobreza en la teología latinoamericana de la liberación y la teología de la prosperidad: apuntes críticos desde la sociología". [Tesis de Licenciatura en Sociología]. San José, Costa Rica: Universidad de Costa Rica, 2008.

Cruz, Marina; Marín, Susana $y$ Santamaría, Geanina. "Dimensiones macroestructurales $y$ psicosociales de la pobreza: percepción de los sujetos que la viven". [Seminario de graduación de Licenciatura en Trabajo Social]. San José, Costa Rica: Universidad de Costa Rica, 2005.
González, Wendy; Jiménez, Alicia y Madrigal, Graciela. "Desarrollo y validación de un instrumento para la medición de la inseguridad alimentaria a nivel del hogar en la comunidad de Concepción de la Unión en el año 2005”. [Tesis de Maestría en Estadística]. San José, Costa Rica: Universidad de Costa Rica, 2006.

Gordon, Gina. "Factores que intervienen en la elección de pareja de convivencia de cinco adolescentes madres que tienen entre 14 y 18 años de edad, que se han desarrollado en condición de pobreza, en la región de Cartago". [Tesisde Licenciatura en Psicología]. San José, Costa Rica: Universidad de Costa Rica, 2010.

Hayes, Liza. "Factores asociados a las tendencias recientes de la pobreza en Costa Rica, 2001-2003". [Tesis de Maestría en Población y Salud]. San José, Costa Rica: Universidad de Costa Rica, 2004.

Hernández, Alejandra; Masís, Natalia y Quesada, Ariela. "Pobreza: concepciones y formas de mediación en Costa Rica (fundamentos éticos, político-ideológicos y teóricos)". [Tesis de Licenciatura en Trabajo Social]. San José, Costa Rica: Universidad de Costa Rica, 2010.

Jones, Jacqueline. "Los recuperadores de Río Azul: exposición de fotografía documental". [Tesis de Licenciatura en Artes Plásticas]. San José, Costa Rica, 2002.

López, Yessenia. "Alcances de promecum en relación con las condiciones de vida de personas egresadas de las escuelas Manuel Belgrano, Cacique Guarco y Las Letras: estudio de casos". [Tesis de Licenciatura en Trabajo Social]. San José, Costa Rica: Universidad de Costa Rica, 2009.

Mondol, Lenin. "Incidencia de las agendas internacionales en los procesos de transformación de política social costarricense enfocados al combate contra la pobreza: período 1998-2006". [Tesis de Licenciatura en Sociología]. San 
José, Costa Rica: Universidad de Costa Rica, 2007.

Monge, Isabel y Rivera, Marta. "Escenarios de la pobreza: convergencia y divergencias, por grupo etáreo y género de personas usuarias de los servicios sociales del IMAS, residentes en zonas urbanas del cantón Central de Cartago". [Tesis de Licenciatura en Trabajo Social]. San José, Costa Rica: Universidad de Costa Rica, 2005.

Mora, Didier y Ramírez, Gerardo. "El crecimiento económico sustentado en el sector exportador y su aporte a la reducción de la pobreza en Costa Rica durante el período 1991-2008". [Tesis de Licenciatura en Economía]. San José, Costa Rica: Universidad de Costa Rica, 2010.

Prado, Gabriela. "La innovación de procesos de trabajo: un desafío social para el Instituto Mixto de Ayuda Social". [Tesis de Maestría en Trabajo Social]. San José, Costa Rica: Universidad de Costa Rica, 2010.

Vargas, Pamela. "Representaciones sociales de la pobreza y de las políticas públicas orientadas a tratarla en el asentamiento precario de Las Palmas, Los Guido, Desamparados, San José, Costa Rica". [Tesis de Licenciatura en Antropología social]. San José, Costa Rica: Universidad de Costa Rica, 2009.

\section{TEXTOS ELECTRÓNICOS}

Doz, Fernanda. "Pobreza y derechos humanos: desde la retórica a las obligaciones legales - una descripción crítica de los marcos conceptuales". Sur. Revista internacional de Derechos Humanos. São Paulo, Brasil. Red Universitaria de Derechos Humanos, 2008. En http:// www.surjournal.org/esp/conteudos/ getArtigo9.php?artigo=9, artigo_doz. html [consultado el 28 de mayo de 2013].
OTROS

Aguilar, Maricarmen y Brenes, Gabriela. "La percepción de riesgo como herramienta para la gestión del riesgo. Aportes para la cogestión comunitaria. Caso de la Comunidad de Sixaola. Limón, Costa Rica".Ponencia presentada en Ix Congreso de Psicología Social para la Liberación. Chiapas, Mexico, 2008b.

Contraloría General de la República de Costa Rica-CGr. "Informe sobre el cumplimiento de las metas establecidas en los contratos con la ciudadanía en el plan nacional de desarrollo 2006-2010, correspondiente al sector social y lucha contra la pobreza". San José, Costa Rica, Contraloría General de la Republica, 2009b.

Contraloría General de la Republica de Costa Rica-cGr. "Informe sobre el diseño y ejecución del programa de transferencia monetaria condicionada denominado 'avancemos'”. San José, Costa Rica. División de Fiscalización Operativa y Evaluativa, Área de Servicios Sociales, Contraloría General de la República, 2008.

Contraloría General de la Republica de Costa Rica-cgr. "Informe sobre el diseño, ejecución y evaluación de las políticas dirigidas hacia la superación de la pobreza”. San José, Costa Rica. División de Fiscalización Operativa y Evaluativa, Área de Servicios Sociales, Contraloría General de al República, 2009a.

Contraloría General de la Republica de Costa Rica-cGr. "Informe sobre el subsidio "servicios básicos para familias en pobreza" del Instituto Mixto de Ayuda Social (mas)". San José, Costa Rica. Dirección Política de los Programas de Asistencia y Promoción social, División de Fiscalización Operativa y Evaluativa, Área de Servicios Sociales, Contraloría General de la República, 2006a.

Contraloría General de la Republica de Costa Rica-cgr. "Primer informe del estudio sobre la organización de los programas 
de asistencia y promoción social. Identificación y caracterización de los programas de asistencia y promoción social $y$ algunas posibilidades de mejorar su integración”. San José, Costa Rica. Dirección Política de los Programas de Asistencia y Promoción social, División de Fiscalización Operativa y Evaluativa, Área de Servicios Sociales, Contraloría General de la República, 2006b.

Contraloría General de la Republica de Costa Rica-cGr. "Segundo informe del estudio sobre la organización de los programas de asistencia y promoción social". San José, Costa Rica. Dirección Política de los Programas de Asistencia y Promoción social, División de Fiscalización Operativa y Evaluativa, Área de Servicios Sociales, Contraloría General de la República, 2006c.

Contraloría General de la Republica de Costa Rica-cGr. "Tercer informe del estudio sobre la organización de los programas de asistencia y promoción social. Gestión de los principales programas de asistencia y promoción social”. San José, Costa Rica. División de Fiscalización Operativa y Evaluativa, Área de Servicios Sociales, Contraloría General de la República, 2007.

Instituto Mixto de Ayuda Social-imas. Reglamento para la Prestación de Servicios y el Otorgamiento de los beneficios que brinda el Instituto Mixto de Ayuda Social (ImAs). San José, Costa Rica: Gobierno de la Republica, 2011.

Reppetti, Gustavo. Pobreza y sujetos sociales. "El papel del Trabajo Social". Semana de Trabajo Social. San José, Costa Rica: Escuela de Trabajo Social, Universidad de Costa Rica, 2013.

Fecha de ingreso: 03/03/2014 Fecha de aprobación: 18/08/2014 
